\title{
Hidden in Plain Sight: Open-Source Occultism in the Age of Information
}

\author{
Cavan McLaughlin
}

\begin{abstract}
In the Information Age, keeping secrets has become increasingly problematic, as both elected officiates and clandestine groups the world over, demonstrate on an almost daily basis. Yet mystery schools, secret societies and occult practices lose none of their popularity; indeed, arguably occulture has enjoyed somewhat of a revival. As the line between private and public life continues to blur, how do such groups, which have long held concealment at the very heart of both their identity and functionality, navigate the sharing culture of the World Wide Web? Within the discourse of Western Esoteric Studies, we frequently find that members of the occult community are oath-bound, even on pain of death and destruction, not to reveal that which Google will instantly share. This chapter will pay particular attention to the rise of the esoteric group Open Source Order of the Golden Dawn (OSOGD), founded in 2002 by Sam Webster, and to Thelema, the philosophy/religion of renowned twentieth century occultist Aleister Crowley. His particular blend of 'Scientific Illuminism' provided Webster with a perfect philosophical underpinning, along with principles from within the open-source software movement, to inform the manifesto of the OSOGD, an online and new Aeonic approach to the old esoteric traditions. Has the time come for the 'occult' to become the 'open' and might the revealing of all secrets be a method of maintaining the mysteries?
\end{abstract}

Key Words: Open-source, occult, occulture, Open Source Order of the Golden Dawn (OSOGD), secrecy.

$* * * * *$

Occult traditions, practitioners and occult practices themselves, have long held concealment at the very heart of both their identity and functionality. The very term occult, of course, derives from the Latin occultus, meaning 'hidden', 'concealed' or 'secret'. Yet, since the onset of the Digital Revolution, and the subsequent meteoric rise of the World Wide Web, it seems almost all aspects of human endeavour and enterprise are entrenched in a continuous and often deeply troubled discourse regarding privacy, publication, information sharing, and the associated repercussions of political, socio-economic and cultural transformation. The world of Western Esotericism and the occult have far from escaped these now almost universal concerns.

Such issues are far from new of course, but rather have been amplified by the arrival of new digital and communication technologies, by many orders of 
magnitude. Given secrecy is a defining characteristic of esoteric tradition, the erosion of privacy now occurring at an unprecedented scale, seems on the face of it, antithetical to its very nature. Yet conspicuously, there are few (in any) contemporary Western Esoteric Traditions, that have not embraced the publicity and connectivity afforded by the Web. Even the most earth-focused and natureloving Wiccans, can be followed online.

Rather than a diminishment of occultism then, what we have in fact witnessed is an occult boom: what Egil Asprem calls 'the rise of the occult information society'. ${ }^{1}$ He attributes the initial cause of this boom directly to the increased, and subsequently free access, to esoteric information and the ever growing dissemination of magical texts. ${ }^{2}$ The exoteric aspects of the Web have opened myriad avenues of digital communication (email, forums, file sharing, blogging, social networking et al) that have facilitated unparalleled acceleration in both exoteric and esoteric discourse: permitting sharing, publishing, research and peer review en masse, and ultimately leading to a multitude of new magical groups and systems. Asprem continues by focusing on such a group:

One illustrative example of the impact of this infrastructural revolution is found in the Open Source Order of the Golden Dawn, established by Sam Webster in 2002 [...]. Reasoning that the digital information revolution makes old institutional frameworks obsolete, this online magical order is based on the free dissemination of magical teachings, democratic leadership, and an open profile regarding which 'traditions' its members bring in and work with. ${ }^{3}$

The radical shift from traditional forms of gatekeeping mass media to a nonhierarchal nexus of horizontal communication, organised around the infrastructure of the Internet and wireless communication, has been enormously catalytic and lies at the the very heart of the fundamental cultural - and thereby occultural transformation seen in the latter part of the Information Age. ${ }^{4}$ Furthermore, this democratization lies at the very heart of what occulture is (and as such, a more thorough and precise definition of occulture will be provided in due course).

Concurrently, new systems of esoteric Order have emerged that actively participate in the embracing of open-source and democratized occultism -in both name and ideological construct. They are open yet occulted; public yet secret. In order to fully understand how such concepts may be paradoxical or oxymoronic yet nevertheless are far from inconsistent, the role of secrecy in the Western Esoteric Tradition requires further analysis.

In relation to Western esotericism, secrecy takes a number of forms and serves a number functions. All of these can first be categorised into two primary orders: incommunicable ineffable secrets and communicable secrets. The former 
refers to the mystical notion that lies at the heart of many esoteric traditions, that there are orders of mystery that can never be communicated. As Antoine Faivre argues, such a secret does not need one to actively keep it, even if materials related to said secret are freely available, it still requires experiential insights and progressive multileveled understanding and penetration. ${ }^{5}$ These insights can only be attained by way of direct experience and as such can never be told. By way of distinction, these ineffable secrets, will hitherto be referred to collectively as the Mysteries.

The latter, however, are mediated; such communicable secrets are closed or disclosed and relate to barriers and the binaries that this infers. They interrelate but can still be sub-categorised as follows:

1) Magical efficacy. Secrecy here is the conservational barrier that is utilized for the purposes of efficacy within a magical operation, inasmuch as, there is 'the widely accepted belief [by practitioners] that magic efficacy wanes with disclosure'. ${ }^{6}$ This is of course incalculable and also presupposes an acceptance in the reality of magical operations, and so will remain beyond the scope of this investigation.

2) Invisibility. This is a perceptual barrier and pertains to the invisible quality of the subject of study itself: the hidden forces of nature. As Wouter Hanegraaff confirms, "Western Esotericism involves the study of nature and its hidden or secret laws and dynamics'. ${ }^{7}$ Literally then, the forces being considered, simply cannot be seen by the human eye that observes them.

3) Safety. Barriers of secrecy are employed for the safety of the practitioner, or indeed, the would-be practitioner. There are two ideas at play here: Firstly, there are the difficulties that may arise from society's reaction to the disclosure of one's involvement in occult practices, and secondly, the concern that esoteric practices themselves may indeed be inherently dangerous, especially if undertaken without proper guidance or understanding.

The first of these issues of safety is easy to understand, especially in a historical context where members of secret societies and occultists may have found their very lives at risk, if they did not keep their practices secret. Even in contemporary society where such practices can sometimes be deemed entirely innocuous, partly due to the mass proliferation of occult ideas, secrecy is still regularly maintained in order to avoid a swathe of negative interactions, consequences and assumptions (even in the OSOGD, non-identity disclosure is expected to be respected unless the individual elects to disclose themselves). ${ }^{8}$ Anonymity then remains essential even in an open-source magical order, but perhaps this is unsurprising, given that 'nondiscrimination' is a core value of the open-source movement. ${ }^{9}$ Freedom to act and communicate without discrimination is ensured by the protections of online anonymity. Moreover, Doug Cowen explains how online anonymity has also helped proliferate esotericism, insofar as, 'online interaction involves identity 
experimentation. [People] try on, as it were, pagan or occult identities, identities that would never be sanctioned in their offline worlds' ${ }^{10}$

The second issue of safety is simply about creating a safe environment for the inexperienced. This is much discussed within the Western Esoteric community, and the desire to conceal information so that it can be introduced in a timely and appropriate fashion is a common reason cited for retaining and managing said secrets. As popular occult author Doreen Valiente asserts, 'many people will tell you that occultism, witchcraft and magic are dangerous. So they are; so is crossing the road; but we shall not get far if we are afraid ever to attempt it. However, we can choose either to dash across recklessly, or to use our common sense and cross with care, and so it is with magic'. ${ }^{11}$

4) Proprietary information. These are barriers relating to ownership. All restricted information can be commodified. Therefore, occult and esoteric intellectual property can also be trade secrets. Indeed, one only needs to consider the enormous market for self-help literature and popular New Age books that promise to confer the secrets of financial success, health, successful relationships and emotional wellbeing that have emerged from the New Thought movement. ${ }^{12}$ Rhonda Byrne's rather aptly titled, The Secret, has been an outstanding commercial success, with estimates of its sales (book and film combined) being $\$ 300$ million. ${ }^{13}$ This commercial aspect is important, because open, in relation to open-source, does not necessarily mean monetarily free. Therefore, issues of publication (in its widest sense) are often still linked with economic factors, for example, even in a digital world, storage and bandwidth cost money.

5) Power dynamic. This particular category may be seen as self-evident, especially given the ubiquity of the aphorism, 'knowledge is power'. Power and its dispensation is in part managed with respect to both secrecy and transparency, once again further complexified in the network intensive digital world. Electronic civil liberty groups and cryptoanarchists fight for both the 'right to know' and the 'right to be unknown'. ${ }^{14}$ In this regard, it is not knowledge per se that is power, but the ability to control access to knowledge that defines the power dynamic. In relation to esoteric knowledge and secret societies, it is noteworthy that a sizeable portion of contemporary society embrace conspiracy theory, or are even adherents to what has recently been coined 'conspirituality'. ${ }^{15}$ Both of the movements are recognized as holding the core conviction that: 'A secret group covertly controls, or is trying to control, the political and social order'. ${ }^{16}$ It is clear that a direct correlation between secrecy and power is firmly embedded in the human psyche.

Each of these forms of mediated secrecy found in Western Esotericism has a function in governing the interrelations that both facilitate and comprise occulture. Furthermore, the precise manner in which occulture is inherently open and democratized, is central to understanding the role open-source occultism has to play in the continuing development of Western Esotericism. It is essential to be clear, therefore, precisely what constitutes occulture. 
Occulture is an new sociological category introduced by Christopher Partridge as a way to make sense of what he deemed to be the 'meaningful confluence' of competing spiritual discourses within popular culture and the media. ${ }^{17}$ On the one hand, with the advent of modernization, widespread desacralization and secularization were clearly evident in the West; yet on the other hand, there remained an equally widespread and conspicuously 'vibrant interest in the paranormal, the pursuit of experiences of transcendence, the acquisition of occult knowledge, and the development of some form of mysticism or inner-life spirituality'. ${ }^{18}$ Occulture, is explicitly not merely occult culture, especially not in the sense of a secretive or fringe culture. Rather, Partridge argues, it is an esoteric, paranormal and spiritual cultural milieu, 'a resource from which people draw, a reservoir of ideas, beliefs, practices and symbols', and crucially, it includes the very institutions, fora and networks that create them. ${ }^{19}$ It is abundantly clear then, that the current occultural revival also has a direct relationship to the exponential growth and complexification of our communication networks. As Asprem clearly elucidates: 'Occulture in this sense is becoming increasingly ordinary and mainstream, especially by functioning as a cultural pool of resources for popular culture'. ${ }^{20}$ The 'meaningful confluence' is paralleled in the terminology itself; occult here, far from implies that occulture is itself hidden. Partridge explicitly clarifies this in his later work on the theory:

Within the idea of "occulture", the "occult" is radically modified by the word "culture". As a compound, "occulture" suggests a democratized occult, an open esotericism - "occulture is ordinary". ${ }^{21}$

The ordinary and everydayness of occulture then, serves not to diminish the esoteric traditions, but rather maintains them. This is precisely the claim made by Jack Bratich, that "within public occulture, revelations do not eliminate the secret, but preserve and extend it'; and thus, 'secret traditions are preserved by being out in the open, hidden in plain sight'. ${ }^{22}$

With respect to these recently formed open esoteric Orders, the purposeful and strategic commitment to public transparency aligns with what Bratich has termed 'spectacular secrecy'. ${ }^{23}$ Moreover, he continues by arguing that 'this spectacular form generalizes secrecy into public and private domains, making revelation no longer the end to secrecy, but its new catalyst' ${ }^{24}$ The ineffable Mysteries cannot be articulated or shared, so necessarily they must transcend culture because they cannot be passed through forms of communication from one generation to the next. As culture transforms, the Mysteries must be continually 'rediscovered' within individuals' personal phenomenological experience. Occulture, however, by way of public secrecy, signposts the Mysteries and preserves their continuous rediscovery. 
Given this link between increased openness and occultural flourishing, and the further connections between public secrecy and its preservation, a case can be made that within the earlier occultural revival of Victorian Britain, the formation of the Hermetic Order of the Golden Dawn and the subsequent publication of its secrets, not only profoundly influenced - but actually served to assist in preserving - what has now been labelled as Western Esotericism. ${ }^{25}$

The Hermetic Order of the Golden Dawn, was initially established in 1888 by William Wynn Westcott and his partners, Dr William Robert and Samuel Liddell MacGregor Mathers. Initially the Golden Dawn's curriculum was based on the 'cipher manuscript', a highly suspicious document that Westcott claimed contained the coded teachings of an ancient German Rosicrucian Lodge. In 1891, a 'Second', or 'Inner Order' formed within the Golden Dawn providing additional teachings derived from personal communications between Mathers and the supposed 'secret chiefs' of the Order. ${ }^{26}$ The legitimacy and authenticity of these secret chiefs became a contributing factor in insurrection and the eventual schism that befell the Order, however, Golden Dawn magic would continue under a number of guises and emergent Orders (Alpha et Omega; Stella Matutina; Independent and Rectified Rite of the Golden Dawn). ${ }^{27}$ Alison Butler describes the Golden Dawn as 'the most significant and influential occult organization of its era, and, arguably, of the last two centuries'. ${ }^{28}$ Whereas the precise measure by which this significance and influence is evaluated is difficult to quantify, the fact that so many Golden Dawn Orders (including of course the Open Source Order of the Golden Dawn) and Golden Dawn-influenced systems still exist today, certainly supports major, if not primary significance. Importantly, the influence that Golden Dawn magic continues to have today comes as a direct result of oath-breaking and the divulging of a huge body of their communicable secrets.

The Golden Dawn's propriety information was made public in 1909 and 1910, in The Equinox, the official periodical of Aleister Crowley's magical order the A $\therefore$ A $\therefore{ }^{29}$ Crowley appealed to the authority of the so-called secret chiefs, in attesting they had released him from his Golden Dawn oaths of secrecy but the publication almost certainly had more to do with his personal notoriety than any sense of democratization because when the next major release of Golden Dawn material was undertaken between 1937-1940 by Israel Regardie, Crowley corresponded with him claiming he had absolutely no right whatsoever to publish the material or to brake his 'sacred obligation to secrecy'. ${ }^{30}$ Regardie, however, explicitly argued that he made the work of the Order available to the public to avoid it being forever lost. ${ }^{31}$ Yet, he also gained monies and notoriety in the process. Whether Regardie's claims to openness are true or spurious, both sets of publications (along with a number of other smaller subsequent releases by various authors) did in fact propagate Golden Dawn teachings and add to the occultural reservoir. Nevertheless, then and now, traditional Golden Dawn oaths explicitly 
forbid the divulging of any information whatsoever, or the perpetrator would submit by their own consent to:

A Stream of Power, set in motion by the Divine Guardians of this Order, $[\ldots]$

They journey as upon the Winds-

They strike where no man strikes-

They slay where no man slays-

and, as I bow my neck under the Sword of the Hiereus, so do I commit myself unto their Hands for vengeance. ${ }^{32}$

In the Open Source Order of the Golden Dawn, oaths of secrecy are no longer taken. It is recognized that previously Hermetically closed secrets are now open public secrets, instantly available through search engines and book stores. Their manifesto endorses following the alleged 'demonstrably advantageous practice of the Open Source Software movement', where the sources of esoteric knowledge, akin to open-source code, should be available to everyone. The Open Source Order of the Golden Dawn are not unique in employing principles of openness, democratization and non-hierarchal structure in contemporary magical groups. For example: there is the Horus-Maat Lodge, a non-hierarchal and authority-rejecting cyberlodge with an open membership and there is even a direct offshoot of the Open Source Order of the Golden Dawn, that is, The Universal Order of the Morning Star.

Furthermore, the reality is, even outside of such groups that actively align themselves with open-source occultism, those groups ostensibly adherent to proprietary based, authoritarian, hierarchical, and change-resistant esoteric traditions are consistently somewhat open-source in their praxis. Free association, open communication and the sharing of esoteric ideas is normative on the online world that they invariably inhabit, even if supposed oaths and principles of initiatic secrecy should indicate otherwise.

Occultism is about the concealed, but correspondingly, it is about revelation, openness and the process of enlightenment, inasmuch as it is about knowledge transfer; whether that be in the sense of direct gnosis of ineffable mystery or the imparting of knowledge: it making the unknown known. As Hanegraaff notes, counter to early theories in sociology, where the occult was viewed as a "disconcerting phenomenon of social "deviance" that seemed to be regressive, in more recent years, the occult is increasingly seen 'as a significant manifestation of modernity'. ${ }^{33}$

Open-source occultism, as a manifestation of the Age of Information, is an evolution of this process on a mass scale, afforded by the exponential growth of horizontal communications networks wherein knowledge transfer can occur. In accordance with the general democratization of knowledge transfer that 
contemporary communications technologies facilitate, Open-source occultism actively participates in and preserves the Mysteries in a very public affirmation of secrecy, ensuring that the ordinary and everydayness of occulture, remains hidden in plain sight.

\section{Notes}

1 Egil Asprem, 'Contemporary Ritual Magic', The Occult World, ed. Chris Partridge (Oxon, New York: Routledge, 2015), 385.

${ }^{2}$ Ibid., 385-386.

${ }^{3}$ Ibid., 386.

${ }^{4}$ From Manuel Castell's seminal work on the topic, The Rise of the Network Society: Economy, Society and Culture vol 1. (Malden, MA, Oxford: WileyBlackwell; 2nd Edition, 2010), xviii.

${ }^{5}$ Antione Faivre, Access to Western Esotericism (Albany: SUNY Press, 1994), 3233.

${ }^{6}$ See Léon A. van Gulik, 'Cleanliness is Next to Godliness, But Oaths are for Horses: Antecedents and Consequences of the Institutionalization of Secrecy in Initiatory Wicca' Pomegranate: The International Journal of Pagan Studies 14.2 (2012): Section 2.3.

${ }^{7}$ Wouter Hanegraaff, Western Esotericism: A Guide for the Perplexed (London, New Delhi, New York, Sydney: Bloomsbury, 2013), 21.

${ }^{8}$ Open Source Order of the Golden Dawn, 'Operational Principles', OSOGD.org, viewed on 12 January 2016. http://osogd.org/about/the-constitution-of-the-opensource-order-of-the-golden-dawn/operational-principles.

${ }^{9}$ Open Source Initiative, 'The Open Source Definition (Annotated): version 1.9', opensource.org, viewed on 21 February 2016.

https://opensource.org/osd-annotated.

${ }_{10}$ Doug E. Cowen, 'The Occult on the Internet', The Occult World, ed. Chris Partridge (Oxon, New York: Routledge, 2015), 533.

${ }^{11}$ Doreen Valiente, Natural Magic (Washington: Pheonix Publishing Inc, 1975), 11.

12 Hanegraaff, Western Esotericism, 39 and a more detailed discussion can be found in Jeremy Rapport's 'Contemporary New Thought', The Occult World, ed. Chris Partridge (Oxon, New York: Routledge, 2015), 216-218 where he notes, 'New Thought in this format [as self-help literature] is enmeshed with the capitalist, free-market exchange system of the modern, Western world. Indeed, much of New Thought's success, such as it is, has depended upon the ability of its proponents to present it as commodity in the marketplace of ideas and practices'.

${ }^{13}$ Exact figures for these sales are not a matter of public record. The figure is derived from the most recent estimated figure published, Melanie Lindner, 'What 
People Are Still Willing To Pay For', forbes.com, 15 January 2009, viewed on 3 February 2016. http://www.forbes.com/2009/01/15/self-help-industry-ent-salescx ml 0115selfhelp.html/.

${ }_{14}$ This phrasing has been adopted from Jack Bratich, 'Popular Secrecy and Occultural Studies' Cultural Studies 21.1 (2007): 53.

15 A phrase coined by Charlotte Ward and David Voas to describe a synthesis between New Age spirituality and conspiracy theory. See Charlotte Ward and David Voas, 'The Emergence of Conspirituality'. Journal of Contemporary Religion 26.1 (2011): 103-121.

16 Ibid., 104. Developed from an earlier work on conspiracy theory by Mark Fenster.

${ }^{17}$ Occulture was first introduced by Christopher Partridge in The Re-Enchantment of the West, vol 1. (London/New York, T\&T Clark: 2004), 62-86. Although he has later recognized the term as coined in the 1980 s by the performance-occultist Genesis P-Orridge, albeit with a quite different inference.

${ }^{18}$ Christopher Partridge, The Occult World (Oxon, New York: Routledge, 2015), 10.

19 Christopher Partridge, The Re-Enchantment of the West, 84; see also the excellent synopsis of Egil Asprem in Arguing with Angels: Enochian Magic and Modern Occulture (Albany: SUNY Press, 2012), 7.

${ }^{20}$ Asprem, Arguing with Angels, 7.

${ }^{21}$ Christopher Partridge, 'Occulture is Ordinary', Contemporary Esotericism, ed. Egil Asprem and Kennet Granholm (Oxon, New York: Routledge, 2014), 119.

${ }^{22}$ Bratich, 'Popular Secrecy and Occultural Studies', 42-58.

${ }^{23}$ Ibid., 43.

${ }^{24}$ Ibid., 45.

${ }^{25}$ See Alison Butler's Victorian Occultism and the Making of Modern Magic: Invoking Tradition (Houndmills, New York: Palgrave Macmillan, 2011) for an extensive discussion of an occult revival in Victorian Britain, especially in her introduction and opening passages of chapter one. Although the term occult revival is used rather that occultural revival, it is clear from our definition that the latter is also true.

${ }^{26}$ This history is widely agreed by scholars and modern Golden Dawn Orders alike. The brief synopsis provided is sourced primarily from Butler's Victorian Occultism, 1-4, and from Frater A.o.C., 'A Short Treatise on the History, Culture and Practices of The Hermetic Order of the Golden Dawn', osogd.org June 21, 2002, viewed on 12 February 2016, http://osogd.org/library/the-aerodynamicbiscuits/a-short-treatise-on-the-history-culture-and-practices-of-the-hermetic-orderof-the-golden-dawn/.

${ }^{27}$ Bulter, Victorian Occultism, 1-4; Frater A.o.C., Culture and Practices of HOGD. 
${ }^{28}$ Butler, Victorian Occultism, 2.

${ }^{29}$ Aleister Crowley, 'The Temple of Solomon the King (Book II)' The Equinox 1.2 (1909): 217-334.; Aleister Crowley 'The Temple of Solomon the King (Book III)' The Equinox 1.3 (1910): 133-280

${ }^{30}$ Israel Regardie, The Golden Dawn: An Account of the Teachings, Rites and Ceremonies of the Order of the Golden Dawn (Llewellyn Publications,U.S.; Revised edition edition 1986), 1.

${ }^{31}$ Frater A.o.C., Culture and Practices of HOGD.

${ }^{32}$ On saying the words, 'Bow my neck' Hiereus (one of the ritual officiates) also places the flat of their sword on the nape of candidate's neck. This excerpt is from the oath taken during the Neophyte Ritual cited from Israel Regardie's, The Golden Dawn, (USA: Llewellyn Publications, Revised 6th edition, 1986), 123.

${ }^{33}$ Hanegraaff, Western Esotericism, 9.

\section{Bibliography}

Asprem, Egil. 'Contemporary Ritual Magic', The Occult World, edited by Chris Partridge. Oxon, New York: Routledge, 2015.

Bratich, Jack. 'Popular Secrecy and Occultural Studies' Cultural Studies 21.1 (2007): 42-58.

Butler, Alison. Victorian Occultism and the Making of Modern Magic: Invoking Tradition. Houndmills, New York: Palgrave Macmillan, 2011.

Castell, Manuel. The Rise of the Network Society: Economy, Society and Culture Vol 1. Malden, MA, Oxford: Wiley-Blackwell; 2nd Edition, 2010.

Cowen, Doug E. 'The Occult on the Internet', The Occult World, edited by Chris Partridge. Oxon, New York: Routledge, 2015.

Crowley, Aleister. 'The Temple of Solomon the King (Book II)' The Equinox 1.2 (1909): 217-334.

—. 'The Temple of Solomon the King (Book III)' The Equinox 1.3 (1910): 133-280.

Faivre, Antione. Access to Western Esotericism, Albany: SUNY Press, 1994. 
Frater A.o.C. 'A Short Treatise on the History, Culture and Practices of The Hermetic Order of the Golden Dawn', osogd.org, June 21, 2002. Viewed on 12 February 2016. http://osogd.org/library/the-aerodynamic-biscuits/a-short-treatiseon-the-history-culture-and-practices-of-the-hermetic-order-of-the-golden-dawn.

Gulik, Léon A. van. 'Cleanliness is Next to Godliness, But Oaths are for Horses: Antecedents and Consequences of the Institutionalization of Secrecy in Initiatory Wicca'. Pomegranate: The International Journal of Pagan Studies 14.2 (2012): 233-255.

Hanegraaff, Wouter. Western Esotericism: A Guide for the Perplexed, London, New Delhi, New York, Sydney: Bloomsbury, 2013.

Lindner, Melanie. 'What People Are Still Willing To Pay For', forbes.com, 15 January, 2009. Viewed on 3 February 2016.

http://www.forbes.com/2009/01/15/self-help-industry-ent-sales-

cx_ml_0115selfhelp.html.

Open Source Initiative, 'The Open Source Definition (Annotated): version 1.9', opensource.org. Viewed on 21 February 2016.

https://opensource.org/osd-annotated.

Open Source Order of the Golden Dawn, 'Operational Principles', OSOGD.org. Viewed on 12 January 2016. http://osogd.org/about/the-constitution-of-the-opensource-order-of-the-golden-dawn/operational-principles.

Rapport, Jeremy. 'Contemporary New Thought', The Occult World, edited by Chris Partridge. Oxon, New York: Routledge, 2015.

Regardie, Israel. The Golden Dawn. USA: Llewellyn Publications, Revised 6th edition, 1986

Valiente, Doreen. Natural Magic. Washington: Pheonix Publishing Inc, 1975.

Cavan McLaughlin is a broadcaster, creative media practitioner and academic with research interests regarding the role of spirituality and occultism in contemporary visual culture. As a media professional of some 14 years he has been involved in almost all aspects of audiovisual production, specialising in music promos and album artwork. 